\title{
A high frequency reflected current signals-based fault type identification method
}

\author{
Shwe Myint, Warit Wichakool \\ Electrical Engineering Department, Prince of Songkla University, Thailand
}

\begin{tabular}{l}
\hline \hline Article Info \\
\hline Article history: \\
Received May 28, 2019 \\
Revised Jul 30, 2019 \\
Accepted Aug 14, 2019 \\
\hline
\end{tabular}

\section{Keywords:}

Discrete wavelet transforms

Fault type identification

Karenbauer transform

Loop distribution system

Time delay

\begin{abstract}
The main objective of this paper is to identify fault type and faulted phase focus on the time delay values of reflected phase and modal current signals. The proposed method identifies fault type with the help of amplitude maxima of detail wavelet coefficient of residual current. The time delay values of phase and modal current reflected signals are used to detect faulty phase instead of using threshold values. Using time delay as a fault type identification parameter is achieved to save the overall protection system operating time because time delay is also the main feature of traveling wave fault location method. Moreover, to ensure the applied wavelet filter, the proposed algorithm is tested with the detail information of the three mother wavelets, such as $\mathrm{db} 4, \mathrm{db} 6$ and $\mathrm{db} 8$ and chosen the highest classification accuracy. Various disturbance events were tested with changing different possible fault types, faulted-feeders, fault resistances, fault locations and fault inception times on a loop distribution system. The robustness of the proposed faulted phase selection algorithm is performed through MATLAB Simulation.
\end{abstract}

Copyright $\odot 2020$ Institute of Advanced Engineering and Science. All rights reserved.

\section{Corresponding Author:}

Warit Wichakool,

Department of Electrical Engineering,

Faculty of Engineering,

Prince of Songkla University, Hat Yai, Thailand.

Email: warit.wi@psu.ac.th

\section{INTRODUCTION}

Fault type and faulted phase identification are necessary in power distribution systems to keep uninterruptable power flow. Correct faulty phase identification is important to prevent switching of the incorrect phase or unnecessary three phase switching. It is also important in power system distribution network to quickly restore the system, improve system reliability, quickly repair the faulted line and reduce operating cost. Classifying the type of fault will help the relay to support several method components related with various fault events. Detecting the correct faulty phase also supports to satisfy single-pole tripping and auto reclosing requirements and to cut down the faulty phase(s). It may lead to increase the stability margin of the power system and possibly prevent needless loss of electricity in some regions.

Most of fault classification methods mainly use various features of wavelet transform (WT) of voltage and current signals from the system measuring terminal. The fault type identification method in [1] classifies different fault types based on wavelet singular entropy (WSE) compared with the predefined threshold values. Local energy (LE) of wavelet transform of voltage waveform is applied in [2]. Moreover, the approximation coefficient-based fault type classification algorithm in [3] is considered based on the approximation coefficients of current traveling waves with the quarter cycle window and the method classify based on wavelet energy entropy (WEE) and wavelet entropy weight (WEW) [4-7], and the recursive wavelet transform method [8]. However, the outcomes of the algorithms in [1-8] are based on threshold values. Some fault type classification methods used the artificial intelligent methods, such as support vector machines 
(SVM) [9-11], artificial neural network (ANN) [12], ANN with the use of particle swarm optimization (PSO) [13] and feedforward neural network combined with S-transform [14]. The fault classification algorithms identify various fault types based on sample values of voltage and current signals compared with their predefined values in [15] and time frequency characteristics of fault waveforms in [16]. Moreover, to enhance performance of directional relaying, fuzzy inference system is used to detect fault type with the help of magnitude of fundamental current and voltage signals [17]. Moreover, combined fuzzy logic and DWT based on the high system reactance to resistance ratio [18] and fuzzy logic based on prefault current and the variation of current [19] are proposed as well. However, the above artificial intelligent (AI) methods using wavelet coefficients are needed to train with the pre-estimated fault conditions. Morphological fault detection algorithms were also introduced in $[20,21]$ using arrival time, polarities and amplitudes of phase voltage and current signals, and polarities of DC component-based method [22]. But these algorithms are complicated to proceed and using polarity to detect faulty phase need to get the signals from both sides of the faulted line. Therefore, these algorithms cannot be used to identify by recording only sigle terminal of loop networks.

The next fault identification methods firstly transform phase to modal components of voltage and current traveling waves and then extract fault features of these modal components with the use of discrete wavelet transform (DWT) filter. Among the various types of modal transform method, Karenbauer transform is used in [23, 24] and Clarke transform is used in [25]. The fault classification methods in [23-25] can be applied to identify various fault types for specified single transmission test system and sampling frequency. However, it cannot be used to detect fault types for multiple transmission systems and distribution networks because it used predefined threshold values for all fault types. The wavelet transform modulus maxima (WTMM) values may change according to fault types, faulted lines, fault distances and sampling frequency. These types of algorithms may not be used to cover for all types of variation which are fault resistance, faulted line, fault inception time and fault location from the measured terminal.

In previous work [26, 27], the amplitude maxima of detail coefficients of modal current components are used to classify fault type and faulty phase by comparing the classification parameters each other according to basic power system fault principles. However, this method may identify wrongly when the magnitude and frequency of the original signals are very small because the detail coefficients represent the high frequency content of the signals.

In this paper, a sample reflected current signal-based fault type classification algorithm is introduced using Karenbauer modal transform and time delay values of phase and modal current reflected signals. This technique utilizes only three-phase current signal from the measured terminal of the network. The approach is divided in to two parts. In the first step, the algorithm will detect the grounded or ungrounded short circuit faults based on the absolute maxima (AM) value of zero modal component. In next step, the algorithm will identify fault type and faulted phase under the grounded or ungrounded situation according to the decision of the previous step by using time delay values of phase and modal reflected current signals.

The paper is organized as follows. Modal transform is presented in section 2. Wavelet transform is illustrated in section 3. Fault type identification is discussed in section 4 and section 5 presents simulation study for faulted phase classification. Section 6 display results and discussions and the last section is conclusion.

\section{MODAL TRANSFORM}

In this study, to identify the fault type, the phase current signals are needed to transform to modal current components to avoid mutual effect among them. All the distribution lines are expected to be fully transposed, and the Karenbauer transformation matrix is applied as a modal transformation matrix which is follows:

$$
\left[\begin{array}{l}
I_{\alpha} \\
I_{\beta} \\
I_{0} \\
I_{\gamma}
\end{array}\right]=\frac{1}{3}\left[\begin{array}{ccc}
1 & -1 & 0 \\
1 & 0 & -1 \\
1 & 1 & 1 \\
0 & 1 & -1
\end{array}\right]\left[\begin{array}{l}
I_{a} \\
I_{b} \\
I_{c}
\end{array}\right]
$$

where $a, b, c$ stand for phase A, B, C respectively and $\alpha, \beta, 0, \gamma$ stand for the modal components. The modal transformation coefficients are real numbers and can be inferred by three phase instantaneous sampling data. This characteristic is very useful for transient signal analysis. The matrix of Karenbauer transform is a fullorder matrix. $\alpha$-modal refers to the line modal between phase "a" and phase "b", $\beta$-modal refers to the line modal between phase "a" and phase "c", 0-modal refers to the residual current component of three-phase current signals and $\gamma$-modal refers to the line modal between phase "b" and phase "c". 


\section{DISCRETE WAVELET TRANSFORM}

The discrete wavelet transforms (DWT) is an effective time-frequency signal-processing tool which can be used to analyze dynamic sampled signals. In past decades, the DWT has been commonly utilized to analyze the dynamic oscillation of power system disturbances.

Basically, the DWT separates the frequency-band of the input signal into low- and high-frequency components, which are called here as approximation and detail coefficients, respectively. In this paper, only arriving times of detail coefficient are used to detect fault type and faulty phase. Given a digital signal function $x(\mathrm{k})$, its coefficients can be computed as follows:

$$
\operatorname{DWT}(m, n)=\frac{1}{\sqrt{a_{0}^{m}}} \sum_{k} x(k) \psi\left(\frac{k-n b_{o} a_{0}^{m}}{a_{0}^{m}}\right)
$$

where $a_{0}$ is the scale factor, $b_{0}$ is the translation factor and $k$ is integer variable and it refers to a sample number of an input signal.

\section{TRAVELING WAVE THEORY}

In the proposed method, the recorded three-phase current waves from the substation are transformed to modal components. The key of this paper is to utilize the arriving time delay between the phases and modal current reflected signals come from fault point. Time delay between zero mode current and phase currents formula in (3) and time delay between zero mode current and modal currents formula in (4) are given as follows:

$$
\begin{aligned}
& \Delta \mathrm{t}_{\mathrm{p}}=\mathrm{t}_{0}-\mathrm{t}_{\mathrm{p}}, \mathrm{p}=\mathrm{a}, \mathrm{b}, \mathrm{c}, \\
& \Delta \mathrm{t}_{\mathrm{m}}=\mathrm{t}_{0}-\mathrm{t}_{\mathrm{m}}, \mathrm{m}=\alpha, \beta, \gamma, \\
& \mathrm{t}_{\mathrm{o}}=\frac{\mathrm{x}}{\mathrm{v}_{\mathrm{O}}}, \\
& \mathrm{t}_{\mathrm{p}}=\mathrm{t}_{\mathrm{m}}=\frac{\mathrm{x}}{\mathrm{v}_{1}}, \\
& \mathrm{v}_{0}=\frac{1}{\sqrt{\mathrm{L}_{0} \mathrm{C}_{0}}} \\
& \mathrm{v}_{1}=\frac{1}{\sqrt{\mathrm{L}_{1} \mathrm{C}_{1}}}
\end{aligned}
$$

where $\Delta \mathrm{t}_{\mathrm{p}}$ and $\Delta \mathrm{t}_{m}$ are the time delay values of phase and modal current reflected signals, $\mathrm{t}_{0}$ is the arriving time of zero mode current traveling wave, $t_{p}$ and $t_{m}$ are the arriving times of phase and modal current traveling wave signals. The arriving times can be calculated from $\mathrm{v}_{0}, \mathrm{v}_{1}$ and $\mathrm{x}$ shown in (5) and (6). $\mathrm{v}_{0}$ and $\mathrm{v}_{1}$ are the velocities of the aerial and zero mode components of traveling waves respectively, and $\mathrm{x}$ is the distance between fault position and measured terminal. These velocities are calculated from characteristic impedance of the distribution line shown in (7) and (8) respectively. $\mathrm{L}_{0}$ and $\mathrm{C}_{0}$ are zero sequence inductance and capacitance of the power line and $L_{1}$ and $C_{1}$ are positive sequence impedance of the power line. When a fault occurs in the system, the characteristic impedance will change according to fault section and faulted phase. At that time, the traveling wave velocities will vary related to characteriatic impedance and the arriving times of all components will differ according to faulty phase. Therefore, the proposed technique used varing patterns of time delay values come from different arriving times related to fault type and faulty phase. 


\section{FAULT TYPE IDENTIFICATION}

The proposed technique is divided in to two parts. In the first part, the algorithm will detect the grounded or ungrounded short circuit faults based on the absolute maxima (AM) value of detail coefficient of zero modal component. The algorithm will finally identify fault type and faulted phase under the grounded or ungrounded situation according to the decision of the previous step by using time delay values of DWT of phase and modal current reflected signals.

\subsection{Grounded or Ungrounded Fault Discrimination}

After recording the fault current signals, the three-phase currents are transformed to the modal components. Next, AM value of detail coefficient of zero model components is applied to decide whether the system is grounded or ungrounded fault. Figure 1 illustrates the flow chart for detecting the grounded and ungrounded faults by zero sequence component.

For appropriate discrimination between grounded and ungrounded conditions, a threshold value $e$ is proposed. This threshold value represents the absolute maxima value of detail coefficient of zero modal because according to theory, the residual current can have under system unbalanced conditions, on the other hand, this value may be zero under system balanced condition. The threshold value should be assumed based on applied system situation and sampling frequency. Therefore, for the test system in this paper according to simulation results, it is found that for grounded cases the value is over $1 \times 10^{-6}$ except for three phase-toground faults. In contrast, for ungrounded faults these values are below $1 \times 10^{-7}$. Therefore, it is chosen to define a definite threshold value $(\varepsilon)$ as $1 \times 10^{-7}$ to cover numerical errors for accurate decision between the two types. In the following flow chart, $\left|\mathrm{d}_{0}\right|$ is absolute maxima (AM) value of detail coefficient of zero sequence current.

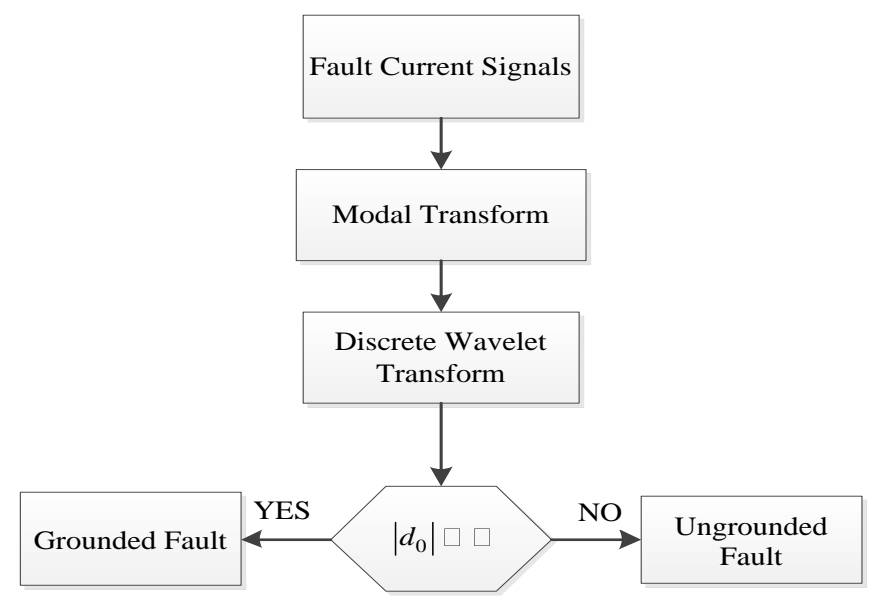

Figure 1. Fault type identification flow chart

\subsection{Classification of Fault Type}

The faulty phase is identified by utilizing six parameters. They are time delay values of phase and modal current reflected signals, $\mathrm{Dt}_{a}, \mathrm{Dt}_{b}, \mathrm{Dt}_{g}, \mathrm{Dt}_{a}, \mathrm{Dt}_{b}$ andDt $c$ receptively. Fault type can be determined using the following procedure:

a. Record current signals at main substation $\left(\mathrm{I}_{\mathrm{a}}, \mathrm{I}_{\mathrm{b}}, \mathrm{I}_{\mathrm{c}}\right)$

b. Transform phase current components to modal components

c. Apply Discrete Wavelet transform (DWT) with db4, db6 and db8 at level 1 and

d. Calculate time delay values $\left(\mathrm{Dt}_{a}, \mathrm{Dt}_{b}, \mathrm{Dt}_{g}, \mathrm{Dt}_{a}, \mathrm{Dt}_{b}\right.$ andDt $\mathrm{t}_{c}$ ) of detail coefficients of all phase and modal current signals.

For grounded fault, firstly the algorithm will check whether system fault is single line to ground (SLG) or two-phase-to-ground (LLG) by using the time delay values of modal current reflected signals $\left(\mathrm{Dt}_{a}, \mathrm{Dt}_{b}\right.$ andDt ${ }_{g}$. The time delay is the time difference between the arriving times of zero mode current 
signal and phase or modal current reflected signals from fault point to the measured substation. If system fault is LLG fault, the time delay values of modal current components must be the same because every modal component are related with one or two faulted phases. In that case, the faulted-phase identification algorithm will detect faulted phases by using the time delay values of phase reflected signals $\left(\mathrm{Dt}_{a}, \mathrm{Dt}_{b}\right.$ andDt $\left.\mathrm{t}_{c}\right)$ and the arriving time of faulted-phase signals may differ from that of the healthy signal. Otherwise, if system fault is SLG fault, the time delay values of a modal component related with two healthy phases may differ from that of other two modal components which are related with this faulted phase. For ungrounded fault, the proposed ungrounded faulted-phase identification algorithm will detect faulted-phase by using the same procedure used in LLG fault.

The grounded faults identification flow charts are described in Figure 2, 3 and 4. In the first step, the algorithm will check whether the fault is SLG or LLG by comparing sum of absolute maxima values of modal components and residual current because the high frequency content of residual current must less than that of sum of all modal components when LLG fault occurs in the system, and this identification procedure is described in Figure 2.

When SLG fault occurs in the system, the classification algorithm displayed in Figure 3 will activate and continuously select the faulted phase. In this process, the modal component related only healthy phases have minimum time delay values because of variation of traveling wave velocity. When a disturbance happens in the system, the traveling wave velocity will vary according to system characteristic impedance via fault assisted. For example, when a SLG (phase A to G) fault occurs in the system, the arriving time of the reflected signal of the faulted phase will arrive later than that of healthy phases depend on fault resistance.

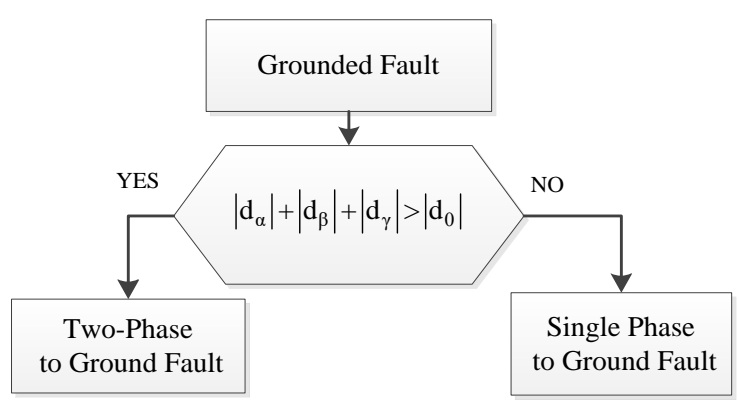

Figure 2. Grounded fault type identification flow chart

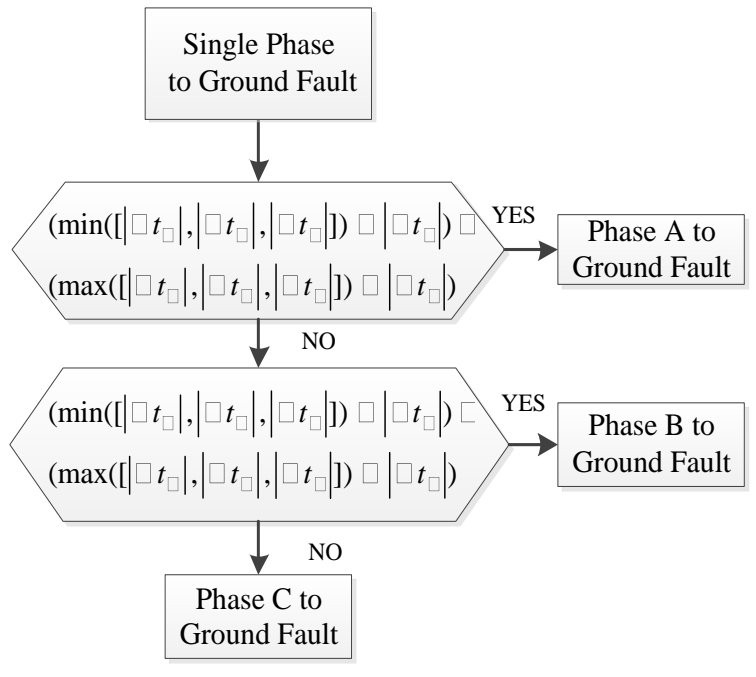

Figure 3. Single line to ground faulted phase identification flow chart

Similarly, the two-phase to ground fault procedure is illustrated in Figure 4. The arriving time of reflected signal of healthy phase may arrive earlier than that of faulty phases. For ungrounded fault, the algorithm will discriminate directly, and the process is shown in Figure 5. If phase to phase fault occurs, the time delay value of the healthy phase current may have less than that of faulted phases because the arriving times of faulted phase will later than that of healthy phase because the traveling wave velocities of healthy and faulted-phase are different as system characteristic impedance is different due to fault. The time delay can be calculated from the arriving times of zero mode and phase current reflected signals. In this algorithm, $\lambda$ is the predefined values of time delay difference between modal current reflected signals. In this paper, the value of $\lambda, 1 \times 10^{-4}$ is assumed because the algorithm will use $\lambda$ to determine whether the time delay difference between modal current signals is zero or not. Therefore, if the time delay diference between modal current signals is zero, the time delay difference values at the specified test cases must greater than $\lambda$. The simulation results and performance of all the proposed algorithms can be seen in the following sections. 


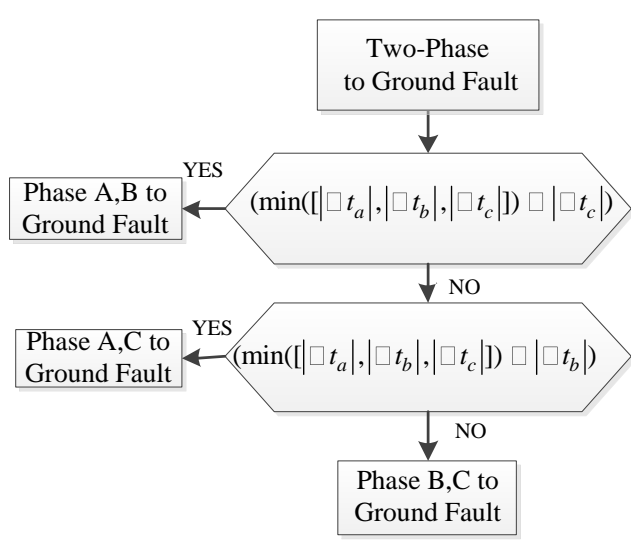

Figure 4. Two line to ground faulted-phase identification flow chart

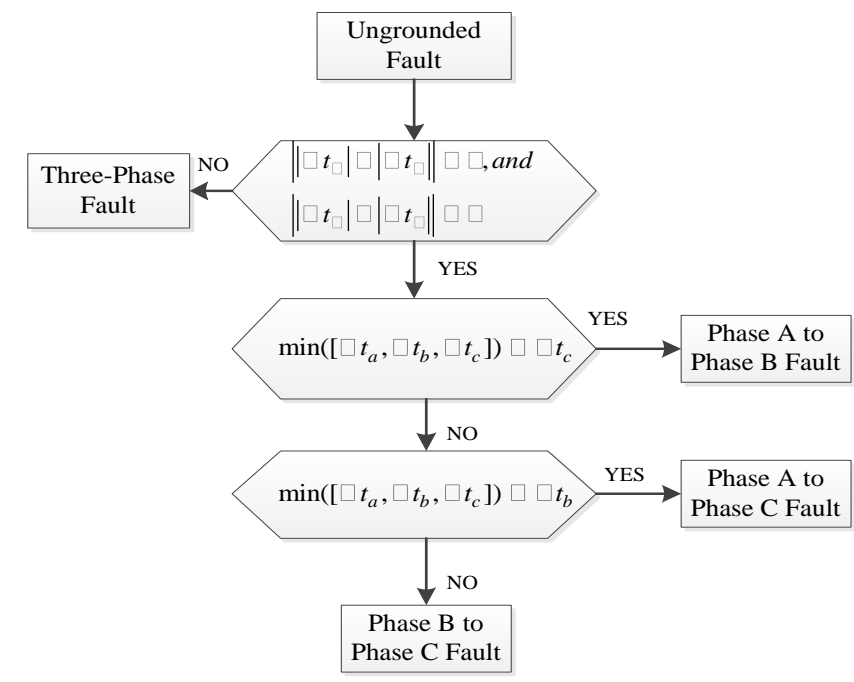

Figure 5. Ungrounded fault type identification flow chart

\section{SIMULATION RESULTS AND DISCUSSIONS}

In this paper, evaluation of fault type identification is evaluated on a power system simulation as demonstrated in Figure 6. The all fault signals of the loop distribution system is generated by using MATLAB SIMULINK program.

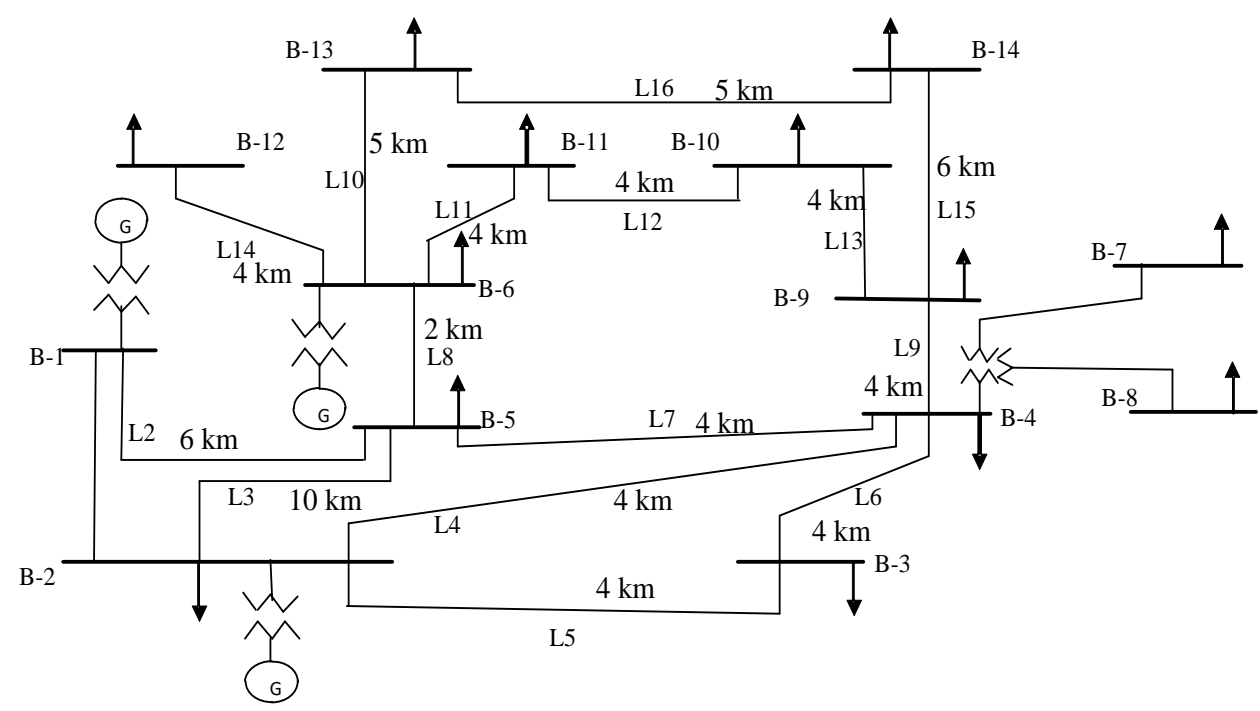

Figure 6. IEEE 14-Bus modified test system

The test network is supported by three power supplies of $33 \mathrm{kV} / 10 \mathrm{kV}, 50 \mathrm{~Hz}$ and a loop overhead distribution system (IEEE 14-bus modified test system). The faults are tested on 16 points on all branches of the test system. All fault types and faulty phases are tested with various fault impedances $\left(\mathrm{R}_{\mathrm{f}}\right)(0.001 \Omega-50 \Omega)$ and different inception time $(0.06 \mathrm{sec}, 0.02 \mathrm{sec}, 0.0005 \mathrm{sec})$ of faults are studied. For every event, the time delay values of phase and modal current reflected signals with mother wavelets (db4, db6 and db8) at level 1 are applied to discriminate fault type and faulted phase. It is found that these values are different for all fault types (SLG, LL, LLG, LLL and LLLG) with different impedances, feeders, locations and inception times. However, maintaining their characteristics of basic theory can be found. The simulation time is $0.1 \mathrm{~s}$ with time step $0.1 \mu \mathrm{s}$. System parameters are generator source resistance $13.96 \Omega$ and source inductance of $0.35 \mathrm{H}$. Distributed line parameter model is used as overhead distribution line parameters. 


\subsection{Determination of Fault Type}

In this section, the fault type and faulty phase are discriminated by using time delay values of phase and modal current reflected signals. The estimated time dealy values are as shown in Figure 7 and 8 as an example. In this example, when phase ' $c$ ' to ground fault happens in the test system, the amplitude maxima of zero sequence current is 0.001829 greater than threshold value $(\varepsilon)$. According to the algorithm shown in Figure 1, system fault is grounded fault. In that case, the time delay values are $\mathrm{Dt}_{a}=9.73^{\prime} 10^{-5}$, $\mathrm{Dt}_{b}=\mathrm{Dt}_{g}=0.0001242$, and these time delay values of modal current signls are not the same and the time delay of phase current are the same. Therefore, fault is SLG fault. For selecting correct faulted phase, the proposed algorithm will determine that the phase with the minium or maximum time delay is as the faulted phase. For this example, system fault is phase ' $c$ ' to ground fault because $\mathrm{Dt}_{a}$ is different from $\mathrm{Dt}_{b}$ andDt $\mathrm{t}_{g}$. Therefore, fault type is single line to ground fault (phase ' $\mathrm{c}$ ' to ground).

The second example is phase ' $b$ ' to phase ' $c$ ' (BC) fault shown in Figure 9. When phase ' $b$ ' to phase ' $\mathrm{c}$ ' fault occurs in the test system, the phase current time delay values are $\Delta \mathrm{t}_{\mathrm{a}}=0.0003129$, $\Delta \mathrm{t}_{\mathrm{b}}=\Delta \mathrm{t}_{\mathrm{c}}=0.0003665$ because the time delay values of modal current signals must be the same and that of faulted-phase current signals must be different from healthy phase current signals according to traveling wave theory. Therefore, the arriving time of phase ' $a$ ' differs from that of other two phases because the traveling wave velocities of healthy and faulted phase are different as system characteristic impedance is different due to fault. This condition means system fault is phase ' $b$ 'to phase ' $c$ ' fault. Other fault types can be identified as this example and test performance of proposed algorithms for various fault types are shown in the following sections.
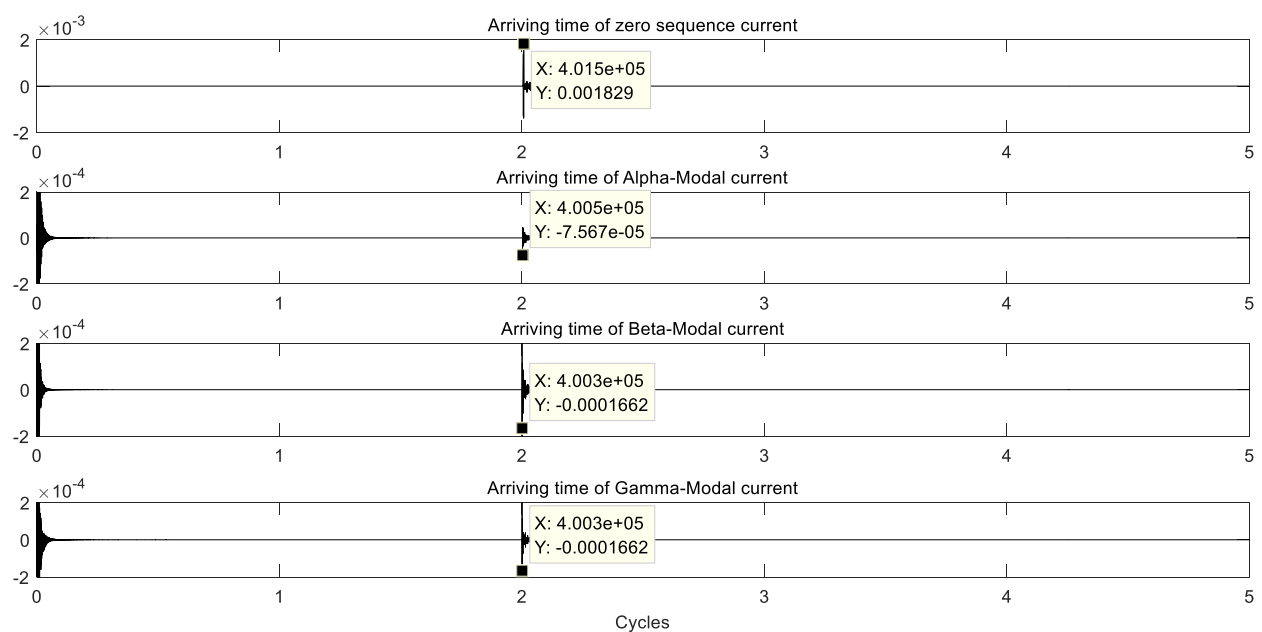

Figure 7. The arriving time of modal current signals under phase 'c' to ground fault condition
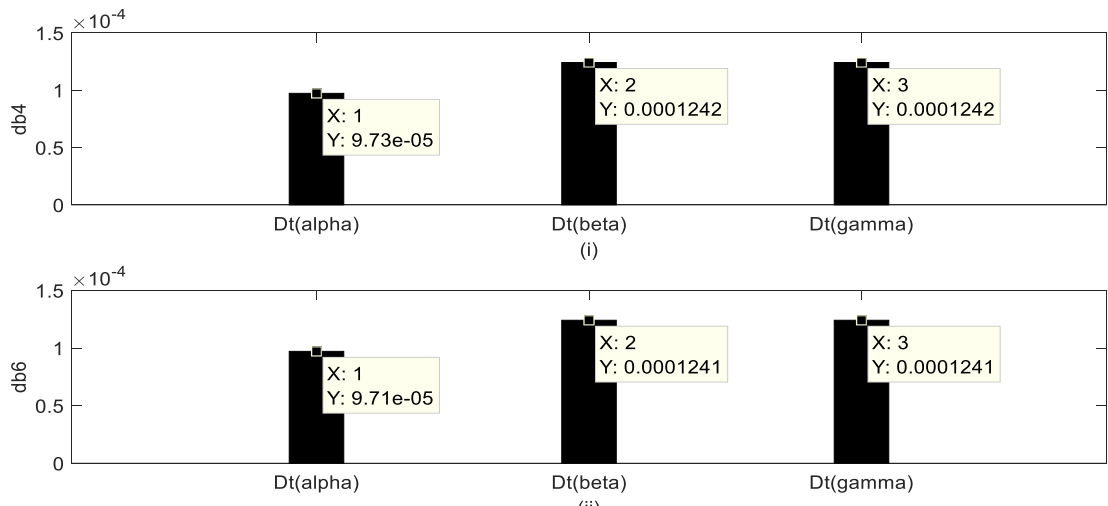

(ii)

Figure 8. The time delay value of reflected modal current signals under phase ' $c$ ' to ground fault condition by different mother wavelets (i) db4 and (ii) db6 


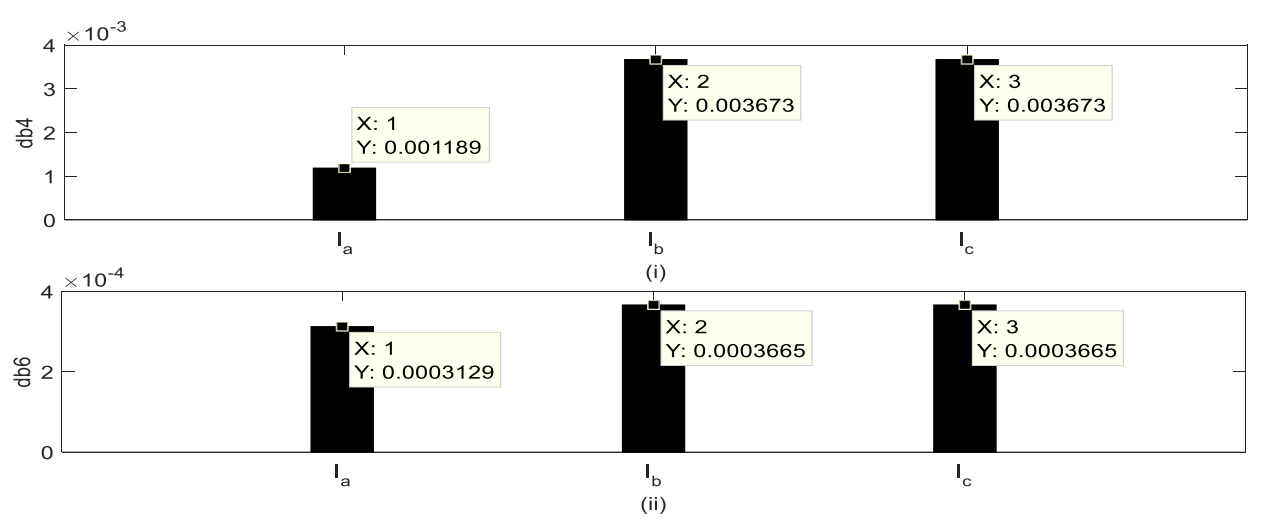

Figure 9. The time delay value of reflected phase current signals under BC fault condition by different mother wavelets (i) db4 and (ii) db6

\subsection{Testing Results of the Proposed Algorithms}

The proposed method is tested with various parameters and shows high accuracy and meeting the condition set for each case with different faulty feeder, different fault resistance $\left(\mathrm{R}_{\mathrm{f}}\right)$, different fault location along the same faulted line and inception time, as illustrated in Tables 1 to 4.

In Table 1, the test results of proposed fault identification algorithm can be seen with minimum and maximum fault resistance conditions. According to this table, the content of high frequency transient can be varied by fault resistance. However, the proposed method can identify correctly because it detects the fault type and faulted phase by comparing the detection parameters each other according to basic principle of power system fault.

In Table 2, the test results of grounded and ungrounded faults are illustrated according to different faulted feeders. The faulted feeder can affect to vary the time delay values of fault type identification parameters because the three-phase current signals are measured from only one substation of the loop distribution grid and the arriving times of faulted and healthy phases can be varied depend on the faulted line of the distribution network.

Similarly, in Table 3 and 4, performance of proposed method with various fault inception times and different fault locations are illustrated respectively. In Table 3, the variation of fault type detection parameters also depends on the fault inception time because if a fault occurs at a time while the original signal crossing zero point (40 milli-sec and 60 milli-sec), there have only the effect of fault transient. Otherwise, when a fault occurs at other non-zero point ( 2.5 milli-sec), the delay time of reflected signal can different depend on the fault inception time. Moreover, according to Table 4, the time delay of phase and modal reflected signals are different according to the fault distance away from the measured terminal. Even though fault occur at the same faulted line and distance, the time delay values of faulted and healthy phases are not the same because their characteristic impedances are the same when a fault happens in the system. In this study, fault occur at the line L7, the fault distance is $1 \mathrm{~km}, 2 \mathrm{~km}$ and $3 \mathrm{~km}$ away from bus B-5, the lowest time delay values can be got when fault occur at the closest distance $(1 \mathrm{~km})$ from the measured terminal.

The proposed algorithm discriminate fault type and faulty phase by comparing the time delay values of all modal and phase reflected signals each other without using a predefined value. Therefore, the proposed method can be used to classify the correct fault type and select faulty phase under various situations, such as various fault resistances, all faulted lines, various inception times and different fault locations along the same faulted line.

Table 1. Performance of Proposed Fault Type Identification Algorithm for all Fault Types with $\mathrm{Rf}=0.001$ ohms and $50 \mathrm{ohms}$

\begin{tabular}{ccccccccc}
\hline $\begin{array}{c}\text { Fault } \\
\text { Type }\end{array}$ & $\begin{array}{c}\mathrm{R}_{\mathrm{f}} \\
(\mathrm{Ohm})\end{array}$ & $\begin{array}{c}\mathrm{D} t_{a} \\
1^{-3}\end{array}$ & $\begin{array}{c}\mathrm{D} t_{b} \\
10^{-3}\end{array}$ & $\begin{array}{c}\mathrm{D} t_{g} \\
10^{-3}\end{array}$ & $\begin{array}{c}\mathrm{D} t_{a} \\
1^{-3}\end{array}$ & $\begin{array}{c}\mathrm{D} t_{b} \\
10^{-3}\end{array}$ & $\begin{array}{c}\mathrm{D} t_{c} \\
10^{-3}\end{array}$ & Result \\
\hline CG & 0.001 & 0.0971 & 0.1241 & 0.1241 & 1.181 & 1.181 & 1.181 & CG \\
CG & 50 & 0.0971 & 0.1241 & 0.1241 & 1.181 & 1.181 & 1.181 & CG \\
BCG & 0.001 & 0.1241 & 0.1241 & 0.1241 & 0.3129 & 0.3665 & 0.3665 & BCG \\
BCG & 50 & 0.1241 & 0.1241 & 0.1241 & 0.3129 & 0.3665 & 0.3665 & BCG \\
BC & 0.001 & 0.3665 & 0.3665 & 0.3665 & 0.3129 & 0.3665 & 0.3665 & BC \\
BC & 50 & 0.3665 & 0.3665 & 0.3665 & 0.3129 & 0.3665 & 0.3665 & BC \\
\hline
\end{tabular}


Table 2. Performance of Proposed Fault Type Identification Algorithm for SLG (AG)

Fault with $\mathrm{R}_{\mathrm{f}}=0.001 \mathrm{ohms}$ for All Branches

\begin{tabular}{ccccccccc}
\hline $\begin{array}{c}\text { Fault } \\
\text { Type }\end{array}$ & $\begin{array}{c}\text { Faulted } \\
\text { Line }\end{array}$ & $\begin{array}{c}\mathrm{D} t_{a} \\
10^{-3}\end{array}$ & $\begin{array}{c}\mathrm{D} t_{b} \\
10^{-3}\end{array}$ & $\begin{array}{c}\mathrm{D} t_{g} \\
10^{-3}\end{array}$ & $\begin{array}{c}\mathrm{D} t_{a} \\
10^{-3}\end{array}$ & $\begin{array}{c}\mathrm{D} t_{b} \\
10^{-3}\end{array}$ & $\begin{array}{c}\mathrm{D} t_{c} \\
10^{-3}\end{array}$ & Result \\
\hline AG & L1 & 0.000 & 0.000 & 3.300 & 0.0001 & 0.0001 & 0.0001 & AG \\
AG & L2 & 0.000 & 0.000 & 3.00 & 0.0001 & 0.0001 & 0.0001 & AG \\
AG & L3 & 0.0989 & 0.0989 & 0.1054 & 0.0001 & 0.0001 & 0.0001 & AG \\
AG & L4 & 0.7030 & 0.7030 & 0.3040 & 0.0001 & 0.0001 & 0.0001 & AG \\
AG & L5 & 0.0586 & 0.0586 & 0.0187 & 0.0001 & 0.0001 & 0.0001 & AG \\
AG & L6 & 0.0937 & 0.0937 & 0.0537 & 0.0001 & 0.0001 & 0.0001 & AG \\
AG & L7 & 0.1241 & 0.1241 & 0.0971 & 0.0001 & 0.0001 & 0.0001 & AG \\
AG & L8 & 0.0821 & 0.0821 & 0.0555 & 0.0001 & 0.0001 & 0.0001 & AG \\
AG & L9 & 0.1173 & 0.1173 & 0.0839 & 0.0001 & 0.0001 & 0.0001 & AG \\
AG & L10 & 0.1173 & 0.1173 & 0.0905 & 0.0001 & 0.0001 & 0.0001 & AG \\
AG & L11 & 0.1173 & 0.1173 & 0.0905 & 0.0001 & 0.0001 & 0.0001 & AG \\
AG & L12 & 0.2245 & 0.2245 & 0.1711 & 0.0001 & 0.0001 & 0.0001 & AG \\
AG & L13 & 0.2245 & 0.2245 & 0.1711 & 0.0001 & 0.0001 & 0.0001 & AG \\
AG & L14 & 0.1173 & 0.1173 & 0.0905 & 0.0001 & 0.0001 & 0.0001 & AG \\
AG & L15 & 0.1591 & 0.1591 & 0.1323 & 0.0001 & 0.0001 & 0.0001 & AG \\
AG & L16 & 0.2403 & 0.2403 & 0.2005 & 0.0001 & 0.0001 & 0.0001 & AG \\
\hline
\end{tabular}

Table 3. Performance of Proposed Fault Type Identification Algorithm for All Fault Types with $\mathrm{R}_{\mathrm{f}}=50$ ohms for Various Fault Inception Time

\begin{tabular}{ccccccccc}
\hline $\begin{array}{c}\text { Fault } \\
\text { Type }\end{array}$ & $\begin{array}{c}\text { Fault } \\
\text { Inception } \\
\text { Time }(\mathrm{sec})\end{array}$ & $\begin{array}{c}\mathrm{D} t_{a} \\
(\mathrm{~ms})\end{array}$ & $\begin{array}{c}\mathrm{D} t_{b} \\
(\mathrm{~ms})\end{array}$ & $\begin{array}{c}\mathrm{D} t_{g} \\
(\mathrm{~ms})\end{array}$ & $\begin{array}{c}\mathrm{D} t_{a} \\
(\mathrm{~ms})\end{array}$ & $\begin{array}{c}\mathrm{D} t_{b} \\
(\mathrm{~ms})\end{array}$ & $\begin{array}{c}\mathrm{D} t_{c} \\
(\mathrm{~ms})\end{array}$ & Result \\
\hline AG & 0.06 & 0.1241 & 0.1241 & 0.0971 & 1.181 & 1.181 & 1.181 & AG \\
AG & 0.04 & 0.1241 & 0.1241 & 0.0971 & 0.0001 & 0.0001 & 0.0001 & AG \\
AG & 0.0205 & 0.1241 & 0.1241 & 0.0971 & 0.0001 & 0.0001 & 0.0001 & AG \\
BCG & 0.06 & 0.1241 & 0.1241 & 0.1241 & 0.0971 & 0.1241 & 0.1241 & BCG \\
BCG & 0.04 & 0.1241 & 0.1241 & 0.1241 & 0.3129 & 0.3665 & 0.3665 & BCG \\
BCG & 0.0205 & 0.1241 & 0.1241 & 0.1241 & 0.0001 & 0.1241 & 0.1241 & BCG \\
BC & 0.06 & 0.0939 & 0.0939 & 0.0939 & 0.0069 & 0.0939 & 0.0939 & BC \\
BC & 0.04 & 0.3665 & 0.3665 & 0.3665 & 0.3129 & 0.3665 & 0.3665 & BC \\
BC & 0.0205 & 0.0939 & 0.0939 & 0.0939 & 0.0469 & 0.0939 & 0.0939 & BC \\
\hline
\end{tabular}

Table 4. Test Results of Proposed Fault Type Identification Algorithm for All Fault Types with $\mathrm{R}_{\mathrm{f}}=50 \mathrm{ohms}$ for Different Fault Distances Along the Line (L7)

\begin{tabular}{ccccccccc}
\hline $\begin{array}{c}\text { Fault } \\
\text { Type }\end{array}$ & $\begin{array}{c}\text { Fault } \\
\text { Distance }\end{array}$ & $\begin{array}{c}\mathrm{D} t_{a} \\
(\mathrm{~ms})\end{array}$ & $\begin{array}{c}\mathrm{D} t_{b} \\
(\mathrm{~ms})\end{array}$ & $\begin{array}{c}\mathrm{D} t_{g} \\
(\mathrm{~ms})\end{array}$ & $\begin{array}{c}\mathrm{D} t_{a} \\
(\mathrm{~ms})\end{array}$ & $\begin{array}{c}\mathrm{D} t_{b} \\
(\mathrm{~ms})\end{array}$ & $\begin{array}{c}\mathrm{D} t_{c} \\
(\mathrm{~ms})\end{array}$ & Result \\
\hline AG & $1 \mathrm{~km}$ & 0.0821 & 0.0821 & 0.0555 & 0.0001 & 0.0001 & 0.0001 & AG \\
AG & $2 \mathrm{~km}$ & 0.1241 & 0.1241 & 0.0971 & 0.0001 & 0.0001 & 0.0001 & AG \\
AG & $3 \mathrm{~km}$ & 0.1056 & 0.0787 & 0.0787 & 0.0001 & 0.0001 & 0.0001 & AG \\
BCG & $1 \mathrm{~km}$ & 0.0821 & 0.0821 & 0.0821 & 0.0555 & 0.0821 & 0.0821 & BCG \\
BCG & $2 \mathrm{~km}$ & 0.1241 & 0.1241 & 0.1241 & 0.3129 & 0.3665 & 0.3665 & BCG \\
BCG & $3 \mathrm{~km}$ & 0.0787 & 0.0787 & 0.1056 & 0.0787 & 0.1056 & 0.0787 & BCG \\
BC & $1 \mathrm{~km}$ & 0.0819 & 0.0819 & 0.0819 & 0.0555 & 0.0819 & 0.0819 & BC \\
BC & $2 \mathrm{~km}$ & 0.3665 & 0.3665 & 0.3665 & 0.3129 & 0.3665 & 0.3665 & BC \\
BC & $3 \mathrm{~km}$ & 0.1055 & 0.1055 & 0.1055 & 0.0785 & 0.1055 & 0.1055 & BC \\
ABC & $1 \mathrm{~km}$ & 0.0555 & 0.0555 & 0.0819 & 0.0555 & 0.0819 & 0.0819 & ABC \\
ABC & $2 \mathrm{~km}$ & 0.0973 & 0.0973 & 0.1173 & 0.0973 & 0.1173 & 0.1173 & ABC \\
ABC & $3 \mathrm{~km}$ & 0.0555 & 0.0555 & 0.0819 & 0.0555 & 0.0819 & 0.0819 & ABC \\
\hline
\end{tabular}

\subsection{Filter Analysis}

In this section, level 1 detail coefficients of the three mother wavelets (db4, db6 and db8) are applied to detect correct fault type and faulty phase, and then compare their outputs and choose the suitable filter with the highest accuracy because the arriving times of reflected signals passed through these three filters may different as these three mother wavelets have different number of non-zero coefficients and different amplitude of non-zero corfficients. The following tables are the comparison outcome of the three mother wavelets with respect to different conditions, such as various fault resistance, different fault inception times, different faulted lines and different fault distance from the measured terminal.

In Table 5, the level 1 detail coefficients of the phase and modal current reflected signals by three mother wavelets are used to classify fault type and faulted-phase for all lines (L1 to L16) of test system by 
creating single line to ground (SLG), phase ' $a$ ' to ground (AG) faults. According to the result of Table 5, the accuracy of db6 is the highest accuracy in those three mother wavelets ( $\mathrm{db} 4, \mathrm{db} 6$ and db8).

In Table 6 , there are eight cases for all fault types with respect to fault resisatnces $(0.001 \mathrm{Wand}$ $50 \mathrm{~W}$ ) by using the detail coefficients of three filters (db4, db6 and db8) respectively. In that case, the proposed algorithm can classify all fault types accuratly and the average fault type and faulted phase identification accuracy for all filters are 100 percent because the value of fault resistance cannot influence on the arriving time via the time delay of phase and modal current reflected signals.

Table 5. Performance of Proposed Fault Type Identification Algorithm for SLG (AG) Fault by using db4, db6 and db8 with $R_{\mathrm{f}}=0.001$ ohms for Different Faulted Lines

\begin{tabular}{|c|c|c|c|c|c|}
\hline \multirow[b]{2}{*}{ Case } & \multirow{2}{*}{$\begin{array}{c}\text { Actual } \\
\text { Fault Type }\end{array}$} & \multirow{2}{*}{$\begin{array}{c}\text { Faulted } \\
\text { Line }\end{array}$} & \multicolumn{3}{|c|}{ Estimated Fault Type by } \\
\hline & & & $\mathrm{db} 4$ & $\mathrm{db} 6$ & $\mathrm{db} 8$ \\
\hline 1 & AG & $\mathrm{L}_{1}$ & AG & $\mathrm{AG}$ & AG \\
\hline 2 & AG & $\mathrm{L}_{2}$ & AG & AG & AG \\
\hline 3 & AG & $\mathrm{L}_{3}$ & AG & AG & CG \\
\hline 4 & AG & $\mathrm{L}_{4}$ & CG & AG & AG \\
\hline 5 & $\mathrm{AG}$ & $\mathrm{L}_{5}$ & AG & AG & CG \\
\hline 6 & AG & $\mathrm{L}_{6}$ & AG & AG & CG \\
\hline 7 & $\mathrm{AG}$ & $\mathrm{L}_{7}$ & AG & AG & AG \\
\hline 8 & AG & $\mathrm{L}_{8}$ & AG & AG & AG \\
\hline 9 & AG & $\mathrm{L}_{9}$ & CG & AG & AG \\
\hline 10 & AG & $\mathrm{L}_{10}$ & CG & AG & $\mathrm{AG}$ \\
\hline 11 & AG & $\mathrm{L}_{11}$ & AG & AG & $\mathrm{AG}$ \\
\hline 12 & AG & $\mathrm{L}_{12}$ & AG & AG & $\mathrm{AG}$ \\
\hline 13 & AG & $\mathrm{L}_{13}$ & AG & AG & CG \\
\hline 14 & AG & $\mathrm{L}_{14}$ & CG & AG & AG \\
\hline 15 & AG & $\mathrm{L}_{15}$ & AG & AG & AG \\
\hline 16 & AG & $\mathrm{L}_{16}$ & AG & AG & CG \\
\hline \multicolumn{3}{|c|}{ Average accuracy (\%) } & 75 & 100 & 68.75 \\
\hline
\end{tabular}

Table 6. Performance of Proposed Fault Type Identification Algorithm for All Fault Types by using db4, db6 and db8 with Different Faulted Resistances at L7

\begin{tabular}{cccccc}
\hline \multirow{2}{*}{ Case } & Actual & Fault resistance & \multicolumn{3}{c}{ Estimated Fault Type by } \\
& Fault Type & $(\mathrm{W})$ & $\mathrm{db} 4$ & $\mathrm{db6}$ & $\mathrm{db} 8$ \\
\hline 1 & $\mathrm{AG}$ & 0.001 & $\mathrm{AG}$ & $\mathrm{AG}$ & $\mathrm{AG}$ \\
2 & $\mathrm{AG}$ & 50 & $\mathrm{AG}$ & $\mathrm{AG}$ & $\mathrm{AG}$ \\
3 & $\mathrm{AG}$ & 100 & $\mathrm{AG}$ & $\mathrm{AG}$ & $\mathrm{AG}$ \\
4 & $\mathrm{ABG}$ & 0.001 & $\mathrm{ABG}$ & $\mathrm{ABG}$ & $\mathrm{ABG}$ \\
5 & $\mathrm{ABG}$ & 50 & $\mathrm{ABG}$ & $\mathrm{ABG}$ & $\mathrm{ABG}$ \\
6 & $\mathrm{ABG}$ & 100 & $\mathrm{ABG}$ & $\mathrm{ABG}$ & $\mathrm{ABG}$ \\
7 & $\mathrm{AB}$ & 0.001 & $\mathrm{AB}$ & $\mathrm{AB}$ & $\mathrm{AB}$ \\
8 & $\mathrm{AB}$ & 50 & $\mathrm{AB}$ & $\mathrm{AB}$ & $\mathrm{AB}$ \\
9 & $\mathrm{AB}$ & 100 & $\mathrm{AB}$ & $\mathrm{AB}$ & $\mathrm{AB}$ \\
& Average accuracy $(\%)$ & & 100 & 100 & 100 \\
\hline
\end{tabular}

The performance of fault type classification with respect to fault inception time $(0.0205,0.04$ and $0.06 \mathrm{sec}$ ) by using three filters is shown in Table 7 . In this case, all the test cases can be detected by three mother wavelets. Similarly, in Table 8. illustrate that the method can select the fault type and faulty phase according to fault distances $(1 \mathrm{~km}, 2 \mathrm{~km}$ and $3 \mathrm{~km}$ of the same faulted line). Although difference locations can get different arriving times, the patterns of time delays for three filters (db4, db6 and db8) are the same for this case. Therefore, the average accuracy is $100 \%$.

According to Table 5 to 8 , the mother wavelet db6 is the most suitable filter for the proposed technique because it has the highest fault type identification accuracy in different faulted lines shown in Table 5, the equal accuracy in other conditions are shown in Table 6, 7and 8, respectively. 
Table 7. Performance of Proposed Fault Type Identification Algorithm for All Fault Types by using db4, db6 and db8 with Different Fault Inception Times at L7

\begin{tabular}{cccccc}
\hline $\begin{array}{c}\text { Ca } \\
\text { se }\end{array}$ & $\begin{array}{c}\text { Actual } \\
\text { Fault Type }\end{array}$ & $\begin{array}{c}\text { Fault Inception } \\
\text { Time }(\mathrm{s})\end{array}$ & $\mathrm{db} 4$ & $\begin{array}{c}\text { Estimated Fault Type by } \\
\text { db6 }\end{array}$ & $\mathrm{db8}$ \\
\hline 1 & BG & 0.0205 & $\mathrm{BG}$ & $\mathrm{BG}$ & $\mathrm{BG}$ \\
2 & $\mathrm{BG}$ & 0.04 & $\mathrm{BG}$ & $\mathrm{BG}$ & $\mathrm{BG}$ \\
3 & $\mathrm{BG}$ & 0.06 & $\mathrm{BG}$ & $\mathrm{BG}$ & $\mathrm{BG}$ \\
4 & $\mathrm{BCG}$ & 0.0205 & $\mathrm{BCG}$ & $\mathrm{BCG}$ & $\mathrm{BCG}$ \\
5 & $\mathrm{BCG}$ & 0.02 & $\mathrm{BCG}$ & $\mathrm{BCG}$ & $\mathrm{BCG}$ \\
6 & $\mathrm{BCG}$ & 0.06 & $\mathrm{BCG}$ & $\mathrm{BCG}$ & $\mathrm{BCG}$ \\
7 & $\mathrm{BC}$ & 0.0205 & $\mathrm{BC}$ & $\mathrm{BC}$ & $\mathrm{BC}$ \\
8 & $\mathrm{BC}$ & 0.04 & $\mathrm{BC}$ & $\mathrm{BC}$ & $\mathrm{BC}$ \\
9 & BC & 0.06 & 100 & 100 & $\mathrm{BC}$ \\
& Average accuracy $(\%)$ & & & 100 \\
\hline
\end{tabular}

Table 8. Performance of Proposed Fault Type Identification Algorithm for All Fault Types by using db4, db6 and db8 with Different Fault Distances at L7

\begin{tabular}{cccccc}
\hline \multirow{2}{*}{ Case } & $\begin{array}{c}\text { Actual } \\
\text { Fault Type }\end{array}$ & $\begin{array}{c}\text { Fault Distance } \\
(\mathrm{km})\end{array}$ & $\mathrm{db} 4$ & $\begin{array}{c}\text { Estimated Fault Type by } \\
\mathrm{db} 6\end{array}$ & $\mathrm{db} 8$ \\
\hline 1 & $\mathrm{BG}$ & 1 & $\mathrm{BG}$ & $\mathrm{BG}$ & $\mathrm{BG}$ \\
2 & $\mathrm{BG}$ & 2 & $\mathrm{BG}$ & $\mathrm{BG}$ & $\mathrm{BG}$ \\
3 & $\mathrm{BG}$ & 3 & $\mathrm{BG}$ & $\mathrm{BG}$ & $\mathrm{BG}$ \\
4 & $\mathrm{ABG}$ & 1 & $\mathrm{ABG}$ & $\mathrm{ABG}$ & $\mathrm{ABG}$ \\
5 & $\mathrm{ABG}$ & 2 & $\mathrm{ABG}$ & $\mathrm{ABG}$ & $\mathrm{ABG}$ \\
6 & $\mathrm{ABG}$ & 3 & $\mathrm{ABG}$ & $\mathrm{ABG}$ & $\mathrm{ABG}$ \\
7 & $\mathrm{AB}$ & 1 & $\mathrm{AB}$ & $\mathrm{AB}$ & $\mathrm{AB}$ \\
8 & $\mathrm{AB}$ & 2 & $\mathrm{AB}$ & $\mathrm{AB}$ & $\mathrm{AB}$ \\
9 & $\mathrm{AB}$ & 3 & $\mathrm{AB}$ & $\mathrm{AB}$ & $\mathrm{AB}$ \\
10 & $\mathrm{ABC}$ & 1 & $\mathrm{ABC}$ & $\mathrm{ABC}$ & $\mathrm{ABC}$ \\
11 & $\mathrm{ABC}$ & 2 & $\mathrm{ABC}$ & $\mathrm{ABC}$ & $\mathrm{ABC}$ \\
12 & $\mathrm{ABC}$ & 3 & 100 & 100 & $\mathrm{ABC}$ \\
& Average accuracy $(\%)$ & & & 100 \\
\hline
\end{tabular}

\section{CONCLUSION}

This paper proposes a simple fault identification technique in loop distribution systems. The proposed technique passed through Karenbauer Transform and Discrete Wavelet Transform filter to estimate a vigorous result for determination of fault type and faulty phase by using only current traveling waves at one source bus of the test distribution network. In all algorithms, the time delay values of modal current reflected signals and phase current reflected signals $\left(\mathrm{Dt}_{a}, \mathrm{Dt}_{b}, \mathrm{Dt}_{g}, \mathrm{Dt}_{a}, \mathrm{Dt}_{b}\right.$ and $\left.\mathrm{Dt}_{c}\right)$ are applied as the fault classification parameters to identify fault type and faulty phase in loop distribution systems which are very complex.

The proposed method classifies the fault type and faulty phase correctly by comparing these classification parameters to each other instead of using threshold values except for identifying whether system fault is grounded or ungrounded case. If threshold values are used for the fault classification process, it need to be defined by evaluating for every test system. However, for the proposed method, the fault type and faulty phase can be classified correctly without defining and evaluating threshold values for every cases and the three mother wavelets (such as $\mathrm{db} 4, \mathrm{db} 6$ and $\mathrm{db} 8$ which are suitable for high frequency power system signals) are used to ensure and improve the reliability of the proposed method. The integrity of the proposed technique is successfully tested with data obtained by MATLAB simulations with various cases of fault current signals at different conditions (faulted feeders, faulted resistance, fault locations and inception times). This proposed technique can be used to implement in real data with actual fault records.

\section{ACKNOWLEDGEMENTS}

The author would like to express her gratitude to their scholarship program, the Higher Education Research Promotion and Thailand's Education Hub for Southern Region of ASEAN Countries (THE-AC). Furthermore, she would like to thank all colleagues from Department of Electrical Engineering, Faculty of Engineering at the Prince of Songkla University. 


\section{REFERENCES}

[1] Z. He, L. Fu, S. Lin, Z. Bo, "Fault detection and classification in EHV transmission line based on wavelet singular entropy," IEEE Trans. Power Delivery, vol. 25, No.4, Oct 2010.

[2] N. Huang, J. Qi, F. Li, D. Yang, G. Cai, G. Huang, J. Zheng, Z. Li, "Short-circuit fault detection and classification using empirical wavelet transform and local energy for electric transmission line" Sensors journal, MPDI, 2017.

[3] B. Rathore, A. G. Shaik, "Wavelet-alienation based transmission line protection scheme", IET Gener. Transm. Distrib., 2017, vol. 11, iss. 4, pp. 995-1003.

[4] Z. He, S. Gao, X. Chen, J. Zhang, Z. Bo, Q. Qian, "Study of a new method for power system transient's classification based on wavelet entropy and neural network", Electric Power and Energy System, 2011, vol. 33, pp. 402-410.

[5] P. Ray, D. P. Mishra, "Support vector machine-based fault classification and location of a long transmission line", Engineering Science and Technology, an International Journal, 2016, vol. 19, pp. 1368-1380.

[6] B. Patel, "A new FDOST entropy based intelligent digital relaying for detection, classification and localization of faults on the hybrid transmission line", Electric Power Systems Research, 2018, vol. 157, pp. 39-47.

[7] V. Ashok, A. Yadav, A. Y. Abdelaziz, "MODWT-based fault detection and classification scheme for cross-country and evolving faults", Electric Power Systems Research, 2019, vol. 175, 105897.

[8] M. I. Zaki, R. A. El-Sehiemy, G. M. Amer, F. M. A. E. Enin, “An investigated reactive power measurements-based fault-identification scheme for teed transmission lines", Measurement, 2019, vol. 136, pp. 185-200.

[9] H. Fathabadi, "Novel filter-based ANN approach for short-circuit faults detection, classification and location in power transmission line", Electric Power and Energy System, 2016, vol. 74, pp. 374-383.

[10] S. S. Gururajapathy, H. Mokhlis, H. A. B. Illias, "Classification and regression analysis using support vector machine for classifying and locating faults in a distribution system”, Turk J Elec Eng \& Comp Sci, 2018, vol. 26, pp. $3044-3056$.

[11] S. S. Gururajapathy, M. H. A. Illias, A. A. Bakar, L. J. Awalin, "Fault identification in an unbalanced distribution system using support vector machine”, J. Electrical Systems, 2016, Vol. 2 Iss. 4, pp. 786-800.

[12] M. Jamil, S. K. Sharma, R. Sigh, "Fault detection and classification in electrical power transmission system using artificial neural network", Jamil et al. SpringerPlus, 2015, vol. 4, pp. 344-357.

[13] J. Upendar, C.P. Gupta, G.K. Singh, G. Ramakrishna, "PSO and ANN based fault classification for protective relaying", IET Gener. Transm. Distrib., 2010, vol. 4, iss. 10, pp. 1197-1212.

[14] M.D. Shafiullah, M.A. Abido, "S-transform based FFNN approach for distribution grids fault detection and classification", IEEE Access, 2018, vol. 6, pp. 8080-8088.

[15] A.G. Shaik, R.R.V. Pulipaka, "A new wavelet-based fault detection, classification and location in transmission lines", Electric Power and Energy System, 2015, vol. 64, pp. 35-40.

[16] X. Qin, P. Wang, Y. Liu, L. Guo, G. Sheng, "Research on distribution network fault recognition method based on time-frequency characteristics of fault waveforms", IEEE Access, 2018, vol. 6, pp. 7291-7300.

[17] A. Yadav, A. Swetapadma, "Enhancing the performance of transmission line directional relaying, fault classification and fault location schemes using fussy inference system", IET Gener. Transm. Distrib. 2015, Vol. 9, Iss. 6, pp. 580-591.

[18] Md. A. Kalam, M. Jamil, "Wavelet-fuzzy based protection scheme of EHV-AC transmissionsystem and efficacy of discrete Fourier transform”, Journal of Electrical System and Information Technology, 2018, vol. 5, pp. 371-387.

[19] A.E.C. Momesso, W.M.S. Bernardes, E.N. Asada, "Fuzzy adaptive setting for time-current-voltage based overcurrent relay in distribution systems", Electrical Power and Energy Systems, 2019, vol. 108, pp. 135-144.

[20] M. Salehi, F. Namdari, "Fault classification and faulted phase selection for transmission line using morphological edge detection filter", IET Gener. Transm. Distrib., 2018, Vol. 12 Iss. 7, pp. 1595-1605.

[21] M. Kavi, Y. Mishra, M. D. Vilathgamuwa, "High-impedance fault detection and classification in power system distribution networks using morphological fault detector algorithm", IET Gener. Transm. Distrib. 2018, Vol. 12, Iss. 15, pp. 3699-3710.

[22] K. Zhu, P.W.T. Pong, "Fault classification of power distribution cables by detecting decaying DC components with magnetic sensing", Transactions on Instrumentation and Measurement, 2019, vol. 18, pp. 9456-9468.

[23] V.S. Kale, S.R. Bhide, P.P. Bedekar, "Faulted phase selection based on wavelet analysis of traveling waves", Int. Nat. Jour. of Comp. and Elect. Eng., 2011, vol. 3, pp. 421-425.

[24] X. Dong, W. Kong, T. Cui, "Fault classification and faulted-phase selection based on the initial current traveling wave", IEEE trans. on Power Delivery, 2009, vol. 24, pp. 552-559.

[25] E.A. Alanzi, M.A. Younis, "A new faulted-phase identification technique for overhead distribution system", Comp. Eng. and Intel. Sys., 2012, vol. 3, iss. 10, pp. 76-85.

[26] S. Myint, W. Wichakool," Fault Type Identification Method based on Wavelet Detail Coefficients of Modal Current Components", Proc. of the 2018 IEEE 5th International Conference on Smart Instrumentation, Measurement and Applications (ICSIMA 2018), 28-30 November 2018, Songkhla, Thailand.

[27] A.R. Adly, R.A. El-Sehiemy, A.Y. Abdelaziz, "A novel single end measuring system based fast identification scheme for transmission line faults", Measurements, 2017, vol. 103, pp. 263-274. 


\section{BIOGRAPHIES OF AUTHORS}

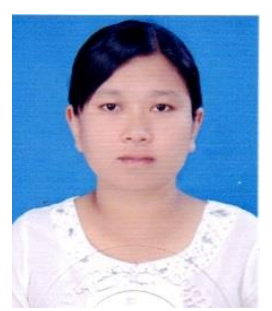

Shwe Myint received the B.E and M.E degrees in electrical engineering from Mandalay Technological University (MTU), Mandalay, Myanmar in 2006 and 2014 respectively. She is currently pursuing the Ph.D. degree program in Electrical Engineering Department at Prince of Songkla University, Hatyai Campus, Songkhla, Thailand. Her current research interests include power system analysis, renewable energy, signal processing and machine learning.

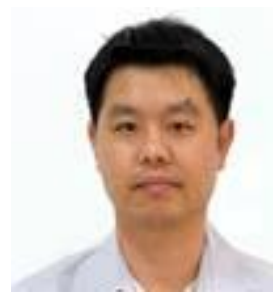

Warit Wichakool received the Ph.D. degree in electrical engineering and computer science from the Massachusetts Institute of Technology, Cambridge, MA, USA, in 2011. He is currently working at Electrical Engineering Department at Prince of Songkla University, Hatyai Campus, Songkhla, Thailand. His current research interests include power system analysis, power converter design, power electronics circuits and applications and renewable energy. 